\title{
Analysis of Road Traffic Accidents in the Punjab by Using Panel Count Data Models
}

\author{
Muhammad Anus Hayat Khan ${ }^{* 1}$ and Ijaz Hussain ${ }^{1}$ \\ Department of Statistics, Quaid-I-Azam University, Islamabad, Pakistan. \\ *Corresponding Author: anashayat_khan40@yahoo.com
}

\begin{abstract}
Each year more than three thousand people die and get serious injuries in traffic accidents. Count data model provide more precise tools for planners and decision makers to conduct proactive road safety planning. We analyzed the exploratory research of Road Traffic Accidents (RTAs) and furthermore explores the factors affecting the RTAs frequency in 36 districts of the Punjab over a time period of three years (July 1, 2013 June 30, 2016) with monthly data using panel count data models. Among the models considered, the random parameters Poisson panel count data model is found to fit the data best. The exploratory analysis shows that highly dense populated districts with large number of registered vehicles causes more accidents as compared to low density populated districts. It is found that, most of the variables used to control the variation in the frequency of RTAs counts play vital role with higher significance levels. The application of regression analysis and modeling of RTAs at district level in Punjab will help to identification of districts with high RTAs rates and this could help more efficient road safety management in the Punjab.
\end{abstract}

Keywords: Road traffic accidents, Panel data, Pooled regression, Fixed effects model, Random effects model, Negative binomial regression, Poisson regression, Random parameters, Punjab.

\section{Introduction}

Worldwide every year, approximately 50 million individuals experience the ill effects of roadway crash episodes, and around 1.2 million individuals endure lethal wounds (World Health et al., 2012). According to Global Status Report on Road Safety 2015 (World Health Organization), road traffic injuries claim more than 1.2 million lives every year and have a huge impact on health and development. They are the leading cause of death among young people aged between 15 and 29 
years, and cost governments approximately 3\% of GDP (Organization, 2015). Other work directed in related territories gauge that backhanded misfortunes to society are around three or four times more prominent than what was sketched out on the world Bank report, while the inability balanced life years lost in all out weight to the creating nations and the overall society is anticipated to be the second and third places by 2020, respectively (Kopits and Cropper, 2005; Eksler et al., 2008). The expenses of road crashes as a percent of GNP shift altogether from nation to nation around the world. It can be as low as $0.5 \%$ as found in Bangladesh, to as high as $4.4 \%$ and $5.7 \%$ for Newzealand and the United States individually (Elvik, 2000). The issue is exacerbated by the way that blunders in police and other related departments information ruin the genuine estimation of the size of the issue (Arif et al., 2015).

In Pakistan, on a normal around 7000 people are died consistently every year as a result of RTAs (Farooq et al., 2011). National Road Safety Secretariat assessed that two million accidents happened in Pakistan in 2006 and 0.418 million were of fatal nature (Ahmed, 2007 ). The counts of RTAs proliferated by 17.5 times between a 30 year time span (1956-1996) while the counts of vehicles are also by 15.8 times between a similar time interval in Pakistan (Jamil, 2008). The financial cost of RTAs in Pakistan was evaluated to be 1.14 billion dollars for 2006 (Ahmed, 2007). Based on earlier literature, the factors that are likely to affect motor vehicle crashes are socio demographic factors, land-use characteristics, roadway-related variables, and traffic characteristics (Kim et al., 2006; Lee et al., 2015b)

Remarkably, 45 thousand individuals die every year on roads in the 27 European Union (EU) nations, with more than 250 billion Euros evaluated as the yearly financial expenses of traffic crashes (Eksler, 2008). However, in Australia the yearly road casualty rate declined from 8 deaths per ten thousand enlisted vehicles to 1 death for each ten thousand vehicles during 1975 to 2008 (Yasmin et al., 2014). Then again, in developing countries like Malaysia, more than 400,000 accidents with 7000 fatalities are accounted for every year bringing about an expected cost of roughly 9 billion Malaysian ringgit in misfortunes to the economy (Hosseinpour et al., 2014). Similarly, road fatalities per capita expanded by 200\% during 1975 to 1998 in Colombia and Botswana (Kopits and Cropper, 2005).

We examined the factors influencing number of accidents with monthly data using random-parameters negative binomial panel count data model and random-parameters Poisson panel count data model. Among models considered, the random parameters model with the correlated coefficients outperformed the other models and was found to fit the data best.

The study was conducted for 36 districts of the Punjab, Pakistan and analyzed the factors affecting counts of RTAs. As, Area wise Punjab is the second largest province of Pakistan and population wise it is the most populous province. $60 \%$ of the entire country population is in the Punjab. With the expanding populace the issue of traffic control has turned out to be extremely intense in most districts of Punjab. The expansion in traffic has likewise expanded the quantity of RTAs and our roads are developing perilous step by step. Lamentably, we have little traffic sense and maybe no regard for the traffic laws. The counts and rates of RTAs are said to fluctuate by 
area, age, sex and type of road user. Of the 1.26 million RTA fatalities in 2000, more than $33 \%$ $(435,000)$ happened in South-east Asia. Albeit South-east Asia has the most astounding extent of RTA fatalities worldwide, Africa has the most astounding RTA demise rate (28 fatalities for each 100,000 people) (Nantulya and Reich, 2002), delineating that the size of the RTA issue fluctuates extensively as indicated by geographic area. The evil wellbeing, or grimness, that out-comes from RTAs likewise contrasts generally by area, with South-east Asia representing more than $33 \%$ of the dismalness because of RTAs every year. When looking at fatalities by level of mechanization, the territorial variety is distinctive; for instance, Sweden has a generally low rate of 1.3 fatalities for each 10,000 vehicles, though the rate is more than 100 fatalities for every 10,000 vehicles in some African nations(Nantulya and Reich, 2002; Afukaar et al., 2003).

Probably, terrible roads and fast driving is the fundamental cause of RTAs. Traffic issue in Punjab is deteriorating with each coming day, particularly in enormous urban areas like Lahore, Rawalpindi, Faisalabad, Gujranwala, Multan, D.G Khan, Sahiwal, Sargodha and Bahawalpur. Objective of the study is To describe the inter-district differences in Road Traffic Accidents (RTAs), To explore the relationship between the RTAs and the population, as well as the number of registered vehicles and some other contributory factors and To provide a defensible guide on how to model the RTAs data.

\section{Material and Methods}

\section{Study Area}

This study uses a 3-year data of Road Traffic Accidents (RTAs) from the 36 districts of the Punjab, Pakistan from 1st July 2013 to 30th June 2016. Source of the data is (Rescue 1122) Headquarters and Bureau of Statistics, Punjab. As, we have the data of three years and our dependent variable and most of independent variables have less variation and did not much fluctuated for such short time period. So, we use the average of dependent variable and independent variables across the years and then utilize the cross sectional data to analyze the accidents counts. Dependent variable in our study is Road Traffic Accidents (RTAs), and the independent variables are Population of the districts, number of registered Vehicles in each district, Precipitation rate of every district, adult Literacy rate in each district, number of health providers (Hospitals) in each district and number of Beds in the hospitals of each district. We have normalized most of our independent variables by the total population in every year for each district and then converted into percentage rates.

\section{Statistical Models}

Models used in this study are Pooled regression model, Fixed effects model, Random effects model, random-parameters Poisson panel count data model and random-parameters Negative Binomial panel count data model.

\section{Pooled Models for Count Data}

The ordinary least squares (OLS) regression without dummy variables is called pooled regression. In pooled regression model we assume a constant intercept and constant slope regardless of firm 
types. A panel data regression differs from a regular time-series or cross-section regression in that it has a double subscript on its variables. This is the pooled OLS regression model as shown below:

$$
Y_{i t}=\beta_{o}+\beta_{i} \mathbf{X}_{i t}+\varepsilon_{i t},
$$

where $\mathrm{i}=1,2,3, \ldots, \mathrm{N}, \mathrm{t}=1,2,3, \ldots, \mathrm{T}, \beta_{o}$ is the intercept, $\beta_{i}$ is the slope, $\varepsilon_{i t}$ is the error term. $\varepsilon_{i t} \sim N\left(0, \sigma_{\varepsilon}^{2}\right)$.

with $i$ denoting individuals, firms, cities, countries, etc. and denoting time. The $i$ subscript, therefore, denotes the cross-section dimension whereas $t$ denotes the time-series dimension. $\mathbf{X}_{i t}$ is the $i$ th observation on $K$ explanatory variables. To estimate the effects of independent variable on our dependent variable, fixed effects model allows us to practice the variations in the variables over time. When there are some omitted variables that may be fixed over time but vary among the cases and others may be constant between cases but changes over time, to include both kinds we use random effects models. The random variable $\left(\beta_{1 i}\right)$ in the random effects model has one value for each unit drawn from the given distribution. The model is written as

$$
Y_{i t}=\alpha+\beta x_{i t}+u_{i t}+\epsilon_{i t}
$$

To examine the nature of road accident,Poisson regression is often used and it has a number of extensions which are useful for count models. Specification for the standard Poisson model is as follows

$$
P\left(Y_{i}=j \mid x_{i}\right)=\frac{\lambda_{i}^{j} e^{-\lambda_{i}}}{j !}, j=0,1,2,3, \ldots
$$

Where $\lambda$ is the expected number of road accidents, we defined it as

$$
\lambda_{i}=E\left[Y_{i} \mid X_{i}\right]=\operatorname{var}\left[Y_{i} \mid X_{i}\right]=\exp \left(X_{i}^{\prime} \beta\right), w \square \text { ere } \lambda_{i}>0 .
$$

Usually,

$$
\lambda_{i}=\exp \left(X_{i}^{\prime} \beta\right)>0 \text { and } Y_{i}=\exp \left(X_{i}^{\prime} \beta\right)+\epsilon_{i}
$$

However, specification for Poisson process is not appropriate and the nature of the process not follows the Poisson in this situation over dispersion may exist. For over dispersed count data or when the conditional variance surpasses the conditional mean, Negative Binomial regression is used to model the count data. Specification for the Negative Binomial Model is stated as

$$
P\left(Y_{i}=j \mid X_{i}\right)=\frac{\Gamma\left(\theta \lambda_{i}+y_{i}\right)}{\Gamma\left(y_{i}+1\right) \Gamma\left(\theta \lambda_{i}\right)} q_{i}^{y_{i}}\left(1-q_{i}\right)^{\theta \lambda_{i}}, j=0,1,2,3, \ldots
$$

where $q=\frac{1}{1(1+\theta)}$

Here, $\theta$ is the Over disperssion parameter and $\Gamma$ is the Gamma function.

\section{Panel Models for Count Data}

Panel models are used if the data contain specific effect of location and are probably to be serially correlated.Specification comprising Random effect and fixed effect for each count model are 
stated as:

The conditional joint distribution for a Poisson-based random-effects model is the following:

$$
P\left(y_{i 1}, \ldots, y_{i T} \mid v_{i}, x_{i}\right)=\left[\prod_{i=1}^{T_{i}} \frac{\lambda_{i t}^{y_{i} t}}{Y_{i} t}\right] \exp \left[-v \sum_{t=1}^{T_{i}} \lambda_{i t}\right]
$$

where $v=\sum_{t=1}^{T_{i}} Y_{i} t, v_{i} \sim \operatorname{Gamma}(\theta, \theta)$ with $E\left[V_{i}\right]=1$ and $V\left[v_{i}\right]=\frac{1}{\theta} V_{i}$ is the random effect for each group $i$.

Use of negative binomial Random-effects models is suitable when variation across groups is random owing to unknown factors. In the standard random-effects case, the dispersion varies randomly across groups according to a beta distribution with parameters $r$ and $s$. The gamma distribution is a special case of the more general beta distribution; it provides the following random-effects negative binomial model.

$$
P\left(y_{i 1}, \ldots, y_{i T_{i}}\right)=\frac{\Gamma(r+s) \Gamma\left(r+\sum_{t=1}^{T_{i}} \lambda_{i t}\right) \Gamma\left(s+\sum_{t=1}^{T_{i}} y_{i} t\right)}{\Gamma(r) \Gamma(s) \Gamma\left(r+s+\sum_{t=1}^{T_{i}} \lambda_{i t} \sum_{t=1}^{T_{i}} y_{i} t\right)} \prod_{i=1}^{T_{i}} \frac{\Gamma\left(\lambda_{i t}+y_{i t}\right)}{\Gamma\left(\lambda_{i t}\right)} \Gamma\left(y_{i t}+1\right)
$$

For a fixed-effects negative binomial model, each group's dispersion parameter can take on any value.

\section{Exploratory Analysis}

Pakistans most populous province is the Punjab with approximately $60 \%$ populace of the country. Area wise Punjab is the second largest province with an area of 205344 square kilometers. Capital city of the Punjab is Lahore and it is also the largest and most populous city. Multan, Faisalabad, Sheikhupura, Sialkot, Gujranwala, Jhelum and Rawalpindi are the other important district's cities. Boundary of the Punjab touches to all other provinces. Total Road Length of the Punjab under National Highway Authority (NHA) and Highway Department, The Punjab in 2013 and 2014 is 75850 Kilometer $(\mathrm{Km})$ and it is $76245 \mathrm{Km}$ in 2015 and 2016. National Highways are $1610 \mathrm{Km}$, Provincial Roads are 16785 Km, District Council Roads are 14735 Km, Farm to Market Roads are $39030 \mathrm{Km}$, Sugar Cess Roads are $3373 \mathrm{Km}$, Motor-Way is $387 \mathrm{Km}$ and Low Type Roads are 325 $\mathrm{Km}$.

We have the monthly data of Road traffic accidents (RTAs) from 36 districts of the Punjab from $1^{\text {st }}$ July 2013 to $30^{t \square}$ June 2016 . We divide the districts into 3 groups on the basis of an accident rates. First group consists of the districts with maximum accidents rates (i.e., Gujranwala, Lahore, Multan), the second group consists of the districts with average accidents rates (i.e., Khanewal, Rawalpindi, Sheikhupura) and in the third group we have districts with minimum accidents rates (i.e., Attock, Muzaffargarh, Vehari), then we compare the RTAs rates within and between the groups. RTAs counts are standardized by the aggregate population and afterward changed over to percentage rates in every month for each district for monthly analysis and in every year for each district for yearly analysis. 

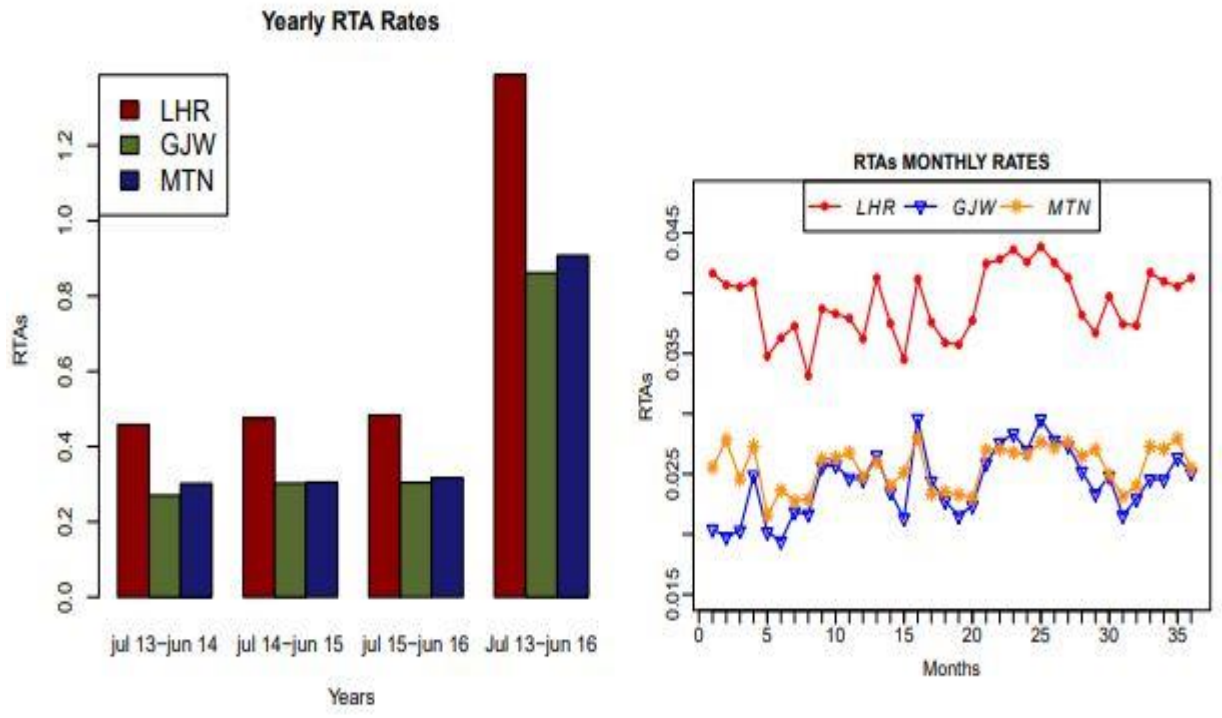

Figure 1: Yearly and monthly RTAs rate

Table 1: Population, No. of Reg.Veh, Roads length and RTAs rates of districts

\begin{tabular}{|c|c|c|c|c|c|}
\hline Cities & & $\begin{array}{l}\text { No. of Reg. } \\
\text { Veh. }\end{array}$ & Roads length & Population & RTAs rates \\
\hline & Jun-14 & 474825 & 2457.23 & 4629000 & 0.2702095 \\
\hline \multirow[t]{3}{*}{ Gujranwala } & Jun-15 & 534905 & 2646.45 & 4707000 & 0.3020608 \\
\hline & Jun-16 & 640423 & 2646.45 & 4774333 & 0.3040424 \\
\hline & Jun-14 & 3022126 & 1244.41 & 9166333 & 0.458264 \\
\hline \multirow[t]{3}{*}{ Lahore } & Jun-15 & 3391268 & 1264.12 & 9350333 & 0.4753627 \\
\hline & Jun-16 & 3991517 & 1264.12 & 9512333 & 0.4832358 \\
\hline & Jun-14 & 832471 & 1976.26 & 4193333 & 0.301407 \\
\hline \multirow[t]{3}{*}{ Multan } & Jun-15 & 919867 & 1976.26 & 4262000 & 0.3049273 \\
\hline & Jun-16 & 1121000 & 1976.26 & 4320333 & 0.3166654 \\
\hline & Jun-14 & 141993 & 2203.03 & 2704333 & 0.1901763 \\
\hline \multirow[t]{2}{*}{ Khanewal } & Jun-15 & 165748 & 2203.03 & 2744666 & 0.229026 \\
\hline & Jun-16 & 214131 & 2203.03 & 2778333 & 0.2413317 \\
\hline
\end{tabular}


Analysis of Road Traffic Accidents in the Punjab by Using Panel Count Data Models

\begin{tabular}{|c|c|c|c|c|c|}
\hline & Jun-14 & 508133 & 3682.75 & 4539000 & 0.2023353 \\
\hline \multirow[t]{3}{*}{ Rawalpindi } & Jun-15 & 580912 & 3687.02 & 4614000 & 0.204443 \\
\hline & Jun-16 & 721868 & 3687.02 & 4678000 & 0.2247542 \\
\hline & Jun-14 & 65778 & 1287.69 & 3027667 & 0.2099636 \\
\hline \multirow[t]{3}{*}{ Sheikhupura } & Jun-15 & 69785 & 1287.69 & 3074666 & 0.232513 \\
\hline & Jun-16 & 75819 & 1287.69 & 3115000 & 0.2362761 \\
\hline & Jun-14 & 66844 & 2178.47 & 1629333 & 0.0898527 \\
\hline \multirow[t]{3}{*}{ Attock } & Jun-15 & 77233 & 2198.03 & 1652000 & 0.0901332 \\
\hline & Jun-16 & 103746 & 2198.03 & 1670333 & 0.0983037 \\
\hline & Jun-14 & 87396 & 3132.06 & 3788667 & 0.0619215 \\
\hline \multirow[t]{3}{*}{ Muzaffargarh } & Jun-15 & 97399 & 3132.06 & 3862333 & 0.0707862 \\
\hline & Jun-16 & 126886 & 3132.06 & 3927666 & 0.0777052 \\
\hline & Jun-14 & 233743 & 2875.29 & 2803000 & 0.0850161 \\
\hline \multirow[t]{2}{*}{ Vehari } & Jun-15 & 265058 & 2875.29 & 2848666 & 0.098081 \\
\hline & Jun-16 & 325352 & 2875.29 & 2887333 & 0.1120411 \\
\hline
\end{tabular}
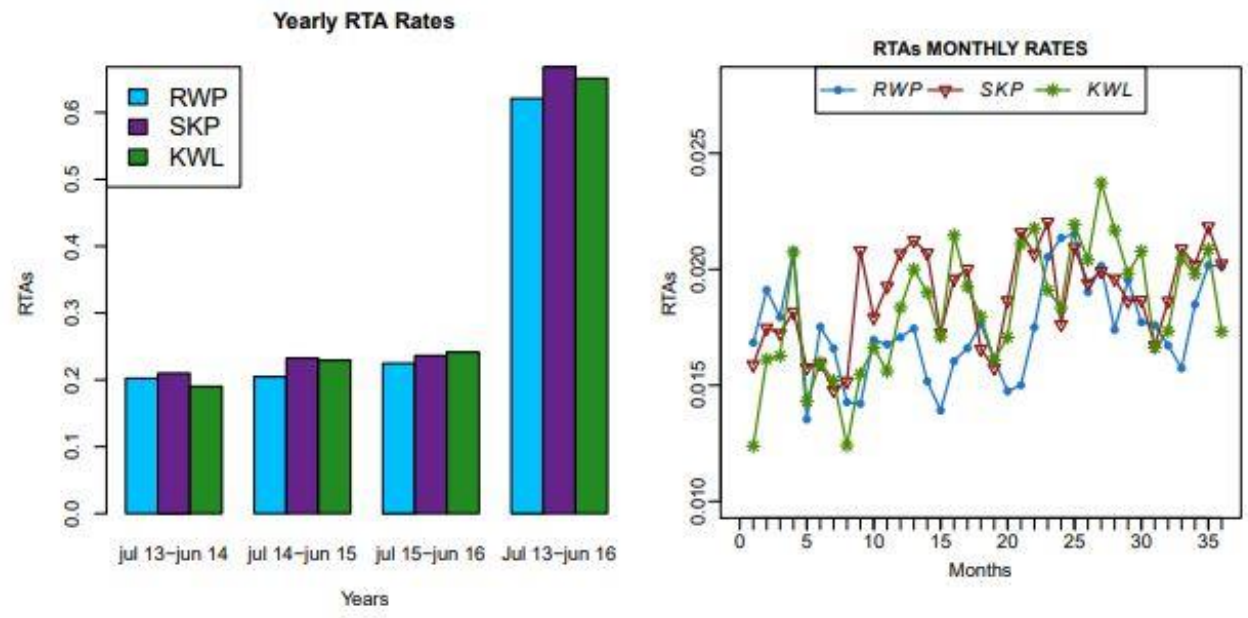

Figure 1: Yearly and monthly RTAs rate 

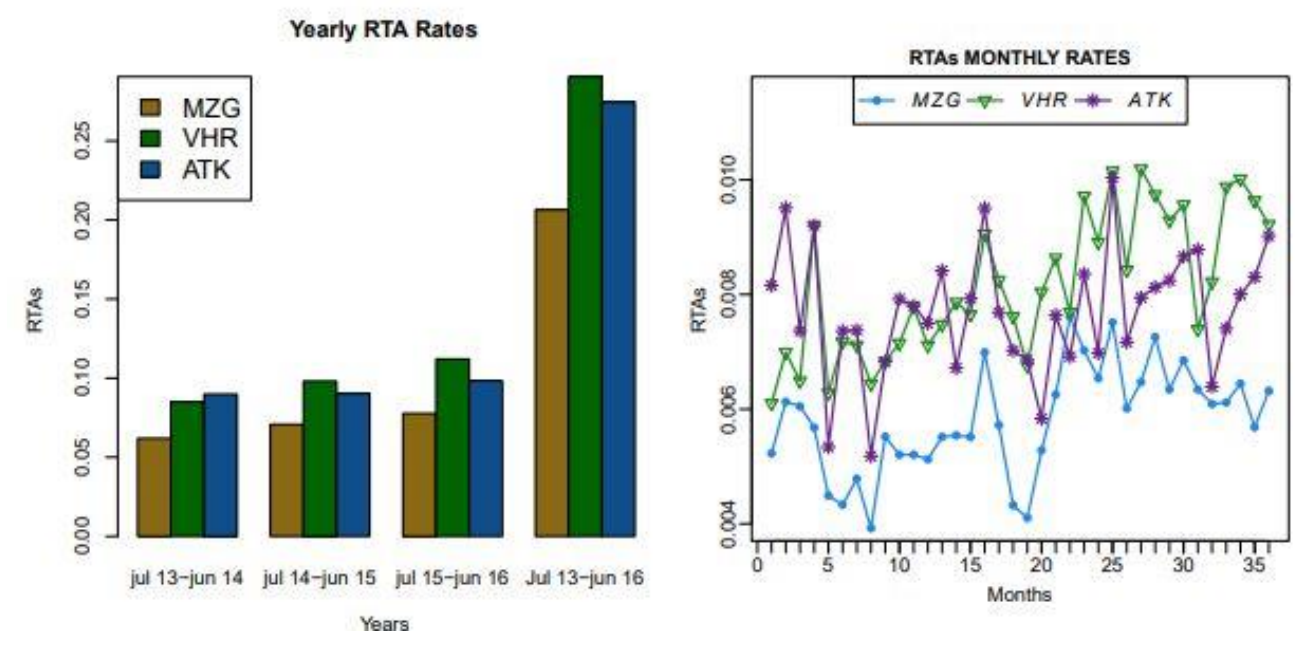

Figure 3: Yearly and monthly RTAs rate

When we examine the RTAs rates by year, we notice that the rate of RTAs has increased during July 2013 to June 2016 Table 1 given above. Population has increased in a large number and the number of registered vehicles on the roads has also increased many time, but the length of the roads is almost same in these districts in the given time span (i.e., July 2013 to June 2016).

Lahore district has the most number of RTAs rates in the Punjab Table 1. It is due to many factors. Population of Lahore district is gradually increasing and the number vehicles are also increasing in a large number day by day causing a heavy traffic jam and troubles. Figure 1, Figure 2 and Figure 3 shows the yearly and monthly RTAs rate of the districts having maximum, average and minimum rate of RTAs. Population plays important role in RTAs, because in third world countries as well as in our study reveals that the highly dense populated districts have more accidents as compared to low density populated districts. This is similar to the studies conducted in India by Sharma (2008) . For example, Lahore is the highly dense populated district of the Punjab with a small area having the maximum RTAs rate. Gujranwala and Multan are also the dense populated cities having the less area as compared to the districts of second and third group with a large number of registered vehicles on the roads. Similarly, districts in the second and third groups also shows the same trend that the RTAs rate depends on the population, number of registered vehicles and the area of the district, i.e., the districts with the large area and less population and number of registered vehicles have the minimum rate of RTAs.

Among the different reasons of traffic issues in districts of the Punjab, a couple are; absence of legitimate framework, terrible roads quality, absence of appropriate transportation framework, infringement of traffic rules, carelessness of traffic wardens, utilizing cell phones while driving, parking and stopping on the main roads and development of business and commercial buildings at the busy and main roads. Other than these reasons, there are some different components which additionally assume a fundamental part in creating this issue. Among 
these components, the critical one is the absence of awareness among individuals about the traffic rules, which are made for their wellbeing and safety. Which is in accordance with the studies conducted before, e.g., Arif et al. (2015).

It is the terrible state of roads, as well as the wrong driving of individuals likewise causes road crashes and mishaps. People mostly violate the traffic rules. They cause distraction in the traffic flow and furthermore turn into a reason of extreme crashes and mischances in which people get harmed and once in a while these accidents and mishaps take away the lives of individuals. It is constantly perilous for life not to obey the traffic rules as it exasperates the traffic balance and flow on the roads. Infringement of traffic rules is dependably aims misfortune for individuals lives and property. This infringement puts your life in threat as well as wind up plainly hazardous for some different lives in the meantime. It likewise bothers the smooth cruising of the traffic which is an extremely hazardous thing. These reasons are similar as studied by Noland (2003).

By giving awareness to the people, it is one of the most imperative steps to solve this issue and it will make them understand the significance of obeying the traffic rules. Traffic wardens and traffic police ought to deal the issues with a better understanding and they should behave in a more educated way, and the traffic rules must be strictly enforced and those who violate these standards should receive punishment and their driving license must be canceled immediately. Batool et al. (2012) has also conducted a study related to RTAs to emphasize the importance of the RTAs study.

\section{Results and Discussion}

We first applied the pooled regression model on our data. R-square is 0.9015 . Only number of beds in the hospitals, number of registered vehicles and population are turned to be significant. We know that number of accidents across different entities (districts) cannot be same, but in above fitted pooled regression model we have considered that number of accidents across different districts are constant. The pooled regression model assumes that the error term both across time and units is uncorrelated and homoscedastic, for which we need some other advanced regression models such as Fixed effects models and Random effects models.

Table 2: Results of fixed effects model and random effects model

\begin{tabular}{|c|c|c|c|c|c|c|c|c|}
\hline RTA & Estimates & Std. Error & $\begin{array}{c}\text { t- } \\
\text { statistic }\end{array}$ & $\begin{array}{c}\text { p- } \\
\text { value }\end{array}$ & Estimates & $\begin{array}{c}\text { Std. } \\
\text { Error }\end{array}$ & $\begin{array}{c}\text { z- } \\
\text { statistic }\end{array}$ & $\begin{array}{c}\text { p- } \\
\text { value }\end{array}$ \\
\hline Hospitals & 2711249 & 5159156 & 0.53 & 0.6 & 2703705 & 3252436 & 0.83 & 0.41 \\
\hline Beds & -617.0234 & 48085.63 & -0.01 & 0.99 & 13380.18 & 25481.91 & 0.53 & 0.6 \\
\hline Vehicles & 48.0481 & 49.7069 & 0.97 & 0.34 & 225.2956 & 33.4666 & 6.73 & 0 \\
\hline Literacy Rate & 0.7767 & 22.7697 & 0.03 & 0.97 & 8.946351 & 21.3047 & 0.42 & 0.68 \\
\hline Population & 0.0097 & 0.0015 & 6.49 & 0 & 0.0034348 & 0.0004 & 8.39 & 0 \\
\hline Precipitation & 0.8315 & 16.2405 & 0.05 & 0.96 & 17.83046 & 16.4563 & 1.08 & 0.28 \\
\hline
\end{tabular}




\begin{tabular}{|l|l|l|l|l|l|l|l|l|}
\hline Constants & -22438.14 & 4471.638 & -5.02 & 0 & -7781.977 & 1766.985 & -4.4 & 0 \\
\hline
\end{tabular}

For fixed effects model R-square is 0.8349 . The model, overall shows significance. Here our time variable only consist three years data and we want to know that RTAs differ over the years which is quite obvious, because population grows rapidly in our districts as well as literacy rate changes. Number of registered vehicles increases over the last few decades and government policies are unable to stop this huge induction of vehicles over roads which cause traffic problems as well as Road traffic accidents. But fixed effects model shows only popualtion as significant variable that the major cause is population growth over the years in RTAs. According to Fixed effect model none of the other independent variables plays significant role in road traffic accidents althogh exploratory analysis shows that RTAs and these independent variables are also cause and effect. To study the other dynamics of the data we need to fit other appropriate panel data models as Random effect model. the Hausmas test was used to distinguish between the fixed effects and random effects model. Under the null hypothesis it assumes that the random effects model, due to higher efficiency is preferred and under the alternative hypothesis fixed effects model is preferred. Results shows that null hypothesis is accepted with p-value 0.9336 , hence we can conclude that random effect model is more appropriate for our panel data and for further panel data analysis we will use only Random effect model.

In random effects model, Wald test is significant for the given independent variables, then the associated parameters with these variables are not zero. So, we include these variables in the model. Random effects regression model shows that the number of registered vehicles and population are significant variables. According to economic theory RTA and number of registered vehicles should have positive relationship and our estimated model shows the coefficient estimate for vehicles as 6.73 with $\mathrm{p}$-value $<0.001$ means highly significant. The estimated coefficient value for population is 8.39 with $\mathrm{p}$-value $<0.001$ which shows high significance of the current variable. The relationship between significant regressors and RTAs the regressand, explains cause and effect as well as explains economic theory. Although literacy rate and precipitation are also important factors in RTAs but random effect model fails to capture this effect as significance, in other words we can say that this sample have insufficient evidence to show these factors as important in explaining road traffic accidents. But for further investigation we should estimate some advanced panel data models such as random parameters Poisson panel count data model and random parameters Negative binomial panel count data model. The value of pesaran's test of cross-sectional independence $=1.256, \operatorname{Pr}=0.2090$ and the average absolute value of the off-diagonal elements $=0.745$. Which shows that null hypothesis is accepted which initially was set as there is cross-sectional independence.

Results of the random parameters negative binomial panel count data model and the random parameters Poisson panel count data model are shown in the following table

Table 3: Results of RPNB-panel count data model and Results of RP-poisson panel count data model 


\begin{tabular}{|c|c|c|c|c|c|c|c|c|}
\hline RTA & Estimates & Std. Error & $\begin{array}{c}\text { z- } \\
\text { statistic }\end{array}$ & p- value & Estimates & Std. Error & $\begin{array}{c}\text { z- } \\
\text { statistic }\end{array}$ & $\begin{array}{c}\text { p- } \\
\text { value }\end{array}$ \\
\hline Hospitals & -521.9417 & 440.716 & -1.18 & 0.236 & -2117.953 & 190.965 & -11.09 & 0 \\
\hline Beds & 5.293562 & 3.254224 & 1.63 & 0.104 & 43.72807 & 2.055816 & 21.27 & 0 \\
\hline Vehicles & 0.0097841 & 0.0052794 & 1.85 & 0.064 & 0.024134 & 0.0017433 & 13.84 & 0 \\
\hline Literacy Rate & 0.0002349 & 0.004156 & 0.06 & 0.955 & 0.0049206 & 0.0007843 & 6.27 & 0 \\
\hline Population & $3.06 e-07$ & $5.36 e-08$ & 5.7 & 0 & $4.52 \mathrm{e}-07$ & $4.91 e-08$ & 9.19 & 0 \\
\hline Precipitation & 0.0051418 & 0.0034283 & 1.5 & 0.134 & 0.005726 & 0.0005491 & 10.43 & 0 \\
\hline Constants & 3.21948 & 0.2842257 & 11.33 & 0 & 6.116091 & 0.1843524 & 33.18 & 0 \\
\hline
\end{tabular}

In both the random parameters Negative binomial panel count data model and the random parameters Poisson panel count data model, Wald test is significant for the given independent variables and the $\mathrm{p}$-value of likelihood ratio test is less than 0.05 . Random parameters Negative binomial panel count data model shows that only the population is significant variable. The relationship between significant independent variable and the dependent variable explains cause and effect and also in accordance with the economic theory. Although the other independent variables are also important factors in RTAs, but random parameters Negative binomial panel count data model fails to capture their effect as significance or simply we can say that this sample have insufficient evidence to show these factors as important in explaining road traffic accidents. Whereas, the random parameters Poisson panel count data model shows that all the regressors, i.e., the number of Hospitals (number of health providers over the district population), number of beds in different hospitals, number of registered vehicles in different districts, district wise adult literacy rate, district population and precipitation rates of the districts are significant variables. Population plays important role in road traffic accidents because the population and the road traffic accidents has the positive relationship as well as our study also shows that highly dense populated districts causes more accidents as compared to low density populated districts. Similarly, with an increase of the number of registered vehicles on the roads RTAs also increases. The study also gives the positive relationship between the RTAs and the number of registered vehicles. Literacy rate also has the highly significant effect on the RTAs as the districts having the higher literacy rate has the low RTAs rate and vice versa. Precipitation variable also has the significant effect as in bad weather, chances of RTAs increases and the districts in which precipitation rate is high, RTAs rate is also higher. We include the variables, number of beds in the hospitals and the number of hospitals in the districts in our model and these also shows the significant effect on the RTAs. As we have the large number of hospitals and bed in the districts, then the number of deaths can be reduced due to RTAs. From these results, it is concluded that random parameters Poisson panel count data model is highly significant and provides a better fit. These findings are echoed with preceding results.

\section{Conclusion}


New advancements in statistical computation methods have prompted analysts applying enhanced techniques to research the impacts of roadway geometric outline and design, ecological elements, and traffic attributes on the frequency of RTAs. The current study included, utilizing aggregated data at a district level to reveal insight into the effects of components influencing the frequency of RTAs crosswise over 36 districts over a three-year time frame with monthly data fragments, utilizing panel count data models. The comparison of these models shows that the random parameters Poisson panel count data model fits the data best in explaining the variation in the RTAs.

The findings from this study are that the number of registered vehicles in different districts, district wise adult literacy rate, district population precipitation rates, number of Hospitals (number of health providers over the district population) and number of beds in different hospitals had positive impacts on the number of RTAs occurrences. The quick increase in the population rate of the districts along with increasing the number of registered vehicles places noteworthy strain on infrastructure of the districts and other administrative services. In this manner, the province needs to build up some counter measures such as, very much planned and well-designed road networks and road infrastructure across the province that is that is maintained over a long term. Given the expected increases in the population and the number of registered vehicles and according to the weather conditions of the districts for meeting future demand for reduction of RTAs and providing safe substitutes would be key components to consider. Strict directions could be implemented to control traffic through more traffic observation cameras focused at roadways to catch the violations of traffic rules. In this study, we discovered that an adult literacy rate also has significant impact on the RTAs rate. By giving awareness to the people and making them to understand the significance of obeying the traffic rules RTAs can be reduced. RTAs data, if appropriately gathered, can give important epidemiological data to screen RTAs in Pakistan. In Pakistan, the RTAS data collection and in addition the registration procedure needs much more improvements. Besides, there ought to be coordination between private health service delivery departments and public and rescue facilities for the collection of data to register all reported RTAs.

So the concluded remarks are that, the induction of more vehicles into national grid causes more accidents and as a remedy government should develop such kind of policies to discourage the more no. of vehicles on roads and should improve national transport system such as metro bus and metro train which have already introduced by current regime and hopes for better results.

Future research should concentrate on multivariate crash numbers and conceivably a spatial statistical modeling approach that includes impacts of heterogeneity among space and time and correlation between them. e.g., one can explore the impacts and factors that at the same time determine the death counts, wounds and only vehicle damaged kind accidents and establishing spatial correlation between the districts together with space and time interaction to check the impact of heterogeneity over time between the districts.

\section{Acknowledgement}

Authors are thankful to the editorial board for their valuable suggestions. 


\section{References}

Afukaar, F. K., Antwi, P., and Ofosu-Amaah, S. (2003). Pattern of road traffic injuries in ghana: implications for control. Injury control and safety promotion, 10(1-2):69-76.

Ahmed, A. (2007). National road safety secretariat ministry of com munications government of pakistan. Road safety in Pakistan. June 21st.

Anwaar, A., Anastasopoulos, P., Ong, G. P., Labi, S., and Islam, M. B. (2012). Factors affecting highway safety, health care services, and motorizationan exploratory empirical analysis using aggregate data. Journal of Transportation Safety \& Security, 4(2):94-115.

Arif, M., Ahmed, M., and Rasool, S. H. (2015). Road traffic accidents. hospital, 2:1-72.

Batool, Z., Carsten, O., and Jopson, A. (2012). Road safety issues in pakistan: a case study of lahore. Transportation planning and technology, 35(1):31-48.

Eksler, V., Lassarre, S., and Thomas, I. (2008). Regional analysis of road mortality in europe. Public health, 122(9):826-837. Elvik, R. (2000). How much do road accidents cost the national economy? Accident Analysis \& Prevention, 32(6):849-851.

Hosseinpour, M., Yahaya, A. S., and Sadullah, A. F. (2014). Exploring the effects of roadway characteristics on the frequency and severity of head-on crashes: Case studies from malaysian federal roads. Accident Analysis \& Prevention, 62:209-222.

Jamali, A. R. (2008). Trauma care in Pakistan. JOURNAL-PAKISTAN MEDICAL ASSOCIATION, 58(3):102. Kopits, E. and Cropper, M. (2005). Traffic fatalities and economic growth. Accident Analysis \& Prevention, 37(1):169-178.

Nantulya, V. M. and Reich, M. R. (2002). The neglected epidemic: road traffic injuries in developing countries. BMJ: British Medical Journal, 324(7346):1139.

Noland, R. B. (2003). Traffic fatalities and injuries: the effect of changes in infrastructure and other trends. Accident Analysis \& Prevention, 35(4):599-611.

Organization, W. H. (2015). Global status report on road safety 2015. World Health Organization.

Sharma, B. (2008). Road traffic injuries: a major global public health crisis. Public health, 122(12):1399-1406.

Yasmin, S., Eluru, N., Bhat, C. R., and Tay, R. (2014). A latent segmentation based generalized ordered logit model to examine factors influencing driver injury severity. Analytic methods in accident research, 1:23-38. 